\title{
Coronary Heart Disease (CHD) Risk Factors and Metabolic Syndrome in HIV-Positive Drug Users in Miami
}

\author{
${ }^{1}$ Marianna K Baum, ${ }^{1}$ Carlin Rafie, ${ }^{3}$ Shenghan Lai, ${ }^{2}$ Lihua Xue, ${ }^{1}$ Sabrina Sales, ${ }^{2}$ J. Bryan Page, \\ ${ }^{1}$ Ronald Berkman, ${ }^{1}$ Linden Karas and ${ }^{1}$ Adriana Campa \\ ${ }^{1}$ Florida International University, College of Health and Urban Affairs \\ ${ }^{2}$ University of Miami School of Medicine, Miami, Florida \\ ${ }^{3}$ Johns Hopkins University, Baltimore, Maryland
}

\begin{abstract}
The frequency of coronary heart disease (CHD) is increasing among HIV seropositive persons. This phenomenon may be related to HIV disease itself, the use of antiretroviral medications and increased length of survival, or the synergism of these factors. In this study we have calculated the 10-year CHD risk estimate and the prevalence of metabolic syndrome in a cohort of 118 HIV seropositive chronic drug users, including those who are on HAART with or without protease inhibitors (PI). The results showed that the 10-year coronary heart disease risk among the HIV seropositive drug users was $4.8 \pm 5.7$, which is within the range of results published for other HIV infected cohorts. The 10-year CHD risk was significantly higher in men $(5.9 \pm 6.1, \mathrm{p}<0.001)$ than in women (1.7 \pm 2.4$)$, due to their gender and the pre-menopausal mean age of the women $(39.4 \pm 7.3$ years of age), despite a significantly higher rate of abdominal obesity (54.8\% in women vs. $8.1 \%$ in men, $\mathrm{p}<0.001)$ and lower HDL $(61.3 \%$ in women vs. $40 \%$ in men, $\mathrm{p}=0.042)$. The rate of metabolic syndrome among our female HIV seropositive drug users was significantly higher (29\% vs $10.3 \%$, $\mathrm{p}=0.013$ ) compared to men (10.3\%). Participants with metabolic syndrome had a significantly higher 10 -year CHD risk ( $27.8 \%$ vs. $10.2 \%, \mathrm{p}=0.041)$ and higher mean BMI $(28.6 \pm 4.1$ vs. $24.2 \pm 4, \mathrm{p}<0.001)$ than those without the syndrome. The predominant proportion of the cohort had a high viral load, suggesting that their use of illicit drugs has an influence on either adherence or effectiveness of antiretroviral medication. Increased viral load was significantly associated with metabolic syndrome $(\mathrm{OR}=2.23,95 \% \mathrm{CI}: 1.12,4.47 ; \mathrm{p}=0.023)$, high fasting glucose $(\mathrm{OR}=1.61,95 \% \mathrm{CI}: 1.02,2.55 ; \mathrm{p}=0.042)$ and low HDL levels $(\mathrm{OR}=1.41,95 \% \mathrm{CI}$ : 1.01, 1.98; $\mathrm{p}=0.046)$, after controlling for age gender, smoking, PI exposure, BMI and CD4. HAART with or without PI did not significantly impact the 10year CHD risk estimate or metabolic syndrome in this cohort. The estimated effect of PI, however, was positively and significantly related to triglyceride levels (effect estimate $=95.81 ; 95 \% \mathrm{CI}: 39.40,152.21$; $\mathrm{p}<0.01)$ after controlling for age, gender, smoking, viral load, CD4 cell count and BMI. Heavy use of cigarettes and crack/cocaine was inversely associated with obesity ( $\mathrm{OR}=0.84,95 \%$ CI:0.67, 0.99; $\mathrm{p}=0.049 ; \mathrm{OR}=0.43,95 \% \mathrm{CI}: 0.19,0.98 ; \mathrm{p}=0.044$, respectively), while use of marijuana tended to be associated with increased central obesity $(\mathrm{p}=0.08)$. Heavy cigarette smoking was significantly associated with low HDL ( $\mathrm{OR}=3.06,95 \% \mathrm{CI}: 1.18 ; 7.95, \mathrm{p}=0.02)$. The significant association of higher viral load with CHD risk indicates that controlling viral load may be important in reducing CHD risk in HIV infected drug users.
\end{abstract}

Key words: Coronary heart disease risk, HIV, metabolic syndrome

\section{INTRODUCTION}

Highly active antiretroviral therapy (HAART) improves the clinical course, prognosis and survival of HIV infected patients. Its prolonged use, particularly with the protease inhibitors, has been associated with an increase in coronary heart disease (CHD) risk $^{[1-3]}$ and with a number of metabolic abnormalities collectively named metabolic syndrome $e^{[4-6]}$. Metabolic syndrome occurs in approximately one quarter of the US general population $^{[7]}$ and in approximately one third of the HIV infected patients ${ }^{[8-10]}$. With the diagnosis of metabolic syndrome, the risk of developing CHD increases threefold and the risk of dying from a heart attack or stroke doubles ${ }^{[11]}$.

Estimate of 10-year coronary heart disease risk uses an algorithm that includes age, gender, blood pressure, total cholesterol and LDL cholesterol, high fasting glucose and smoking status ${ }^{[12]}$. While a number of studies have been published to demonstrate metabolic abnormalities and CHD risk in HIV seropositive cohorts ${ }^{[11,13-17]}$, to our knowledge no reports focus on cohorts of HIV infected drug users and the contribution of illicit drugs to CHD risk. Moreover,

Corresponding Author: Marianna K. Baum, Ph.D., Florida International University, Stempel School of Public Health, University Park, Room HLS 337, Miami, Florida 33199, Tel: 305-348-2871, Fax: 305-348-0383 
the factors used to estimate CHD risk in the drug abusing population may not be accurate as the drug abuse itself significantly increases the risk ${ }^{[18]}$. In this study we have calculated the 10-year CHD risk estimate and the prevalence of metabolic syndrome in a cohort of HIV seropositive chronic drug users, including those who are on HAART with or without protease inhibitors.

\section{MATERIALS AND METHODS}

Study design: A cross-sectional study was carried out on a cohort of 118 HIV infected drug users recruited between March, 2002 and December, 2003 from the Camillus House, a non-profit organization that provides services to the poor in Miami, Florida. The study protocol was approved by the Florida International University Internal Review Board and consisted of a physical examination including a medical history and laboratory analyses after a 12-hour fast. Documented HIV seropositive status, age 18 to 55 years or older and active drug use (determined by urine toxicology) were inclusion criteria for the study. Sociodemographic, alcohol and drug abuse data were collected. All participants gave written informed consent prior to enrollment in the study.

Participant examination protocol: Physical examination and medical history were performed by a nurse practitioner after determination of eligibility. The data collection tools emphasized the history of infectious illness, diabetes, coronary artery vascular disease and hypertension. Drug history included currently prescribed medications, as well as frequency and quantity of cigarette smoking, alcohol consumption and illicit drug use in the previous 6 months. Height, weight and waist circumference were obtained using standard methods and blood pressure was measured in the left arm with the elbow flexed to heart level. Venous blood was drawn for CD4 cell count, viral load, blood chemistry and lipid panel; urine was collected for toxicology.

Biochemical assays: Lymphocyte phenotype was determined with four-color immunophenotyping panel of monoclonal antibodies. Differential counts were determined using a Coulter MaxM hematology instrument and corroborated with cytocentrifuge smears. Viral load was obtained by the reverse transcriptase polymerase reaction using the Roche Amplicor reagents and protocol. Triglycerides, total cholesterol and HDL were determined directly using the Aeroset ${ }^{\mathrm{TM}}$ System (Abbott Laboratories), with calculation of LDL and VLDL levels. C-reactive protein was determined using the CRP Ultra Range Reagent Kit (Equal Diagnostics), a latex-enhanced turbidimetric immunoassay.

Definition of 10-year cardiovascular risk and metabolic syndrome: The 10-year CHD risk was determined using the algorithm derived from the Framingham study to estimate cardiovascular risk in the general population ${ }^{[12]}$. The risk factors included in the Framingham calculation of 10-year risk are: age, gender, total cholesterol, HDL cholesterol, systolic blood pressure, treatment for hypertension, elevated fasting glucose and cigarette smoking.

Metabolic syndrome was defined according to the guidelines of the National Cholesterol Education Program (NCEP) Adult Treatment panel ATP $\mathrm{III}^{[4]}$. Participants having $\geq 3$ of the following factors were defined as having metabolic syndrome: waist circumference $>102 \mathrm{~cm}$ in men and $88 \mathrm{~cm}$ in women, serum triglycerides $\geq 150 \mathrm{mg} / \mathrm{dL}$, high density lipoprotein (HDL) cholesterol $\leq 40 \mathrm{mg} / \mathrm{dL}$ in men and $\leq 50 \mathrm{mg} / \mathrm{dL}$ in women; blood pressure $\geq 130 / 85 \mathrm{mmHg}$; and serum glucose $\geq 110 \mathrm{mg} / \mathrm{dL}$.

Statistical analysis: This is a crossectional study that explores the associations of HIV disease, antiretroviral treatment and drugs of abuse and CHD risk in a cohort of HIV seropositive drug users in Miami. Our analyses first focused on the calculation of the 10-year CHD risk for the total cohort and by gender using the 10-year risk $\%$ derived from the Framingham multiple-risk-factor equation $^{[12]}$ and the NCEP Adult Treatment panel ATP III guidelines to diagnose metabolic syndrome ${ }^{[4]}$. We compared the rate of 10 -year CHD risk and the parameters of disease progression, frequency of drug of abuse, treatment and characteristics of the participants diagnosed with metabolic syndrome to those of participants without the syndrome. The association of parameters of HIV disease (viral load and CD4 cell count), antiretroviral treatment (HAART with and without PIs) and drugs of abuse (alcohol, tobacco, cocaine and marijuana) with CHD risks were examined using univariate analyses. The significant factors were subsequently included in complex regression models adjusting for other significant variables.

Descriptive statistics were used to characterize the population. Student's t-test was used to evaluate the mean differences and $\chi^{2}$ tests were used to evaluate percentage differences. Wilcoxon rank sum tests were used when data were not normally distributed. Univariate analyses were used to assess association between CHD risk factors and parameters of HIV disease status, antiretroviral treatment and the type and frequency of substances abused. Logistic regressions and MANOVA were performed for multivariate analyses.

\section{RESULTS}

Characteristics of the population: The cohort of 118 HIV seropositive drug users consisted of $74 \%$ males and $83.2 \%$ were Black. The mean age of the cohort was $41.69 \pm 6.85 \mathrm{SD}$. Their mean income was US $\$ 393 \pm 83$ $\mathrm{SD}$ and the mean years of education for the cohort were $11.36 \pm 2.66 \mathrm{SD}$. Of the total cohort, $71 \%$ were on 
HAART and $36.5 \%$ were receiving protease inhibitors. The mean CD4 count was $333 \pm 262$ cells $/ \mathrm{mm}^{3}$ SD $\left(316 \pm 238\right.$ cells $/ \mathrm{mm}^{3}$ SD for men and $382 \pm 320$ cells $/ \mathrm{mm}^{3} \mathrm{SD}$ for women), mean viral load was $9.3 \pm$ $2.4 \log \mathrm{SD}(9.2 \pm 2.5 \log \mathrm{SD}$ for men, $9.6 \pm 2.2 \log \mathrm{SD}$ for women) and the mean C-reactive protein (CRP) was $4.8 \pm 7.8 \mathrm{mg} / \mathrm{L} \mathrm{SD}(7.9 \pm 12.8 \mathrm{mg} / \mathrm{L} \mathrm{SD}$ for men, $4.4 \pm$ $6.9 \mathrm{mg} / \mathrm{L} \mathrm{SD}$ for women). Daily alcohol consumption was reported by $57.6 \%$ of the cohort, while $83.9 \%$ smoked cigarettes, $38.1 \%$ used marijuana and $67.8 \%$ used cocaine/crack. There were no significant differences between the genders in any of these characteristics, although women showed a marked trend ( $\mathrm{p}=0.08)$ towards using more marijuana than men.

Risk factors for coronary heart disease and metabolic syndrome: As Table 1 shows, the 10-year CHD risk in this cohort of HIV seropositive drug users was $4.8 \pm 5.7$; the women had significantly lower 10 year CHD risk $(1.7 \pm 2.4, \mathrm{p}<0.001)$ than men $(5.9 \pm 6.1)$. The prevalence of the metabolic syndrome, on the other hand was significantly higher in women (29\%, $\mathrm{p}=0.013)$ compared to men $(10.3 \%)$. The factors influencing this higher prevalence of metabolic syndrome among women included a significantly higher rate of abdominal obesity (54.8\% in women vs. $8.1 \%$ in men, $\mathrm{p}<0.001)$ and lower HDL $(61.3 \%$ in women vs. $40 \%$ in men, $\mathrm{p}=0.042$ ).

Table 2 shows that participants with metabolic syndrome had a significantly higher estimate of 10-year CHD risk of $\geq 10 \%(27.8 \%, \mathrm{p}=0.041)$ than those without metabolic syndrome $(10.2 \%)$. The risk factors significantly associated with the metabolic syndrome were male gender $(\mathrm{OR}=0.28$, 95\% CI: 0.10, 0.80; $\mathrm{p}=0.017)$, Body Mass Index (OR=1.19, 95\% CI:1.07, $1.32 ; \mathrm{p}=0.001$ ), which was significantly higher in those with metabolic syndrome $(28.6 \pm 4.1, \quad \mathrm{p}<0.001)$ compared to those without the syndrome $(24.2 \pm 4)$ and viral load ( $\mathrm{OR}=1.61,95 \% \mathrm{CI}: 1.02,2.54 ; \mathrm{p}=0.042)$. The paradox of the women having lower CHD risk while having higher prevalence of the metabolic syndrome appears to arise from the separate algorithm used for calculating the 10-year CHD risk for women that also takes into consideration their pre-menopausal age, resulting in a lower estimate of the CHD risk for women than men. On the other hand, the definition of metabolic syndrome does not take gender and age into consideration, causing the apparent contradiction in this cohort of the women having lower 10-year CHD risk while having a higher prevalence of metabolic syndrome than men. The analyses, however, indicate that those with metabolic syndrome have a significantly higher 10-year CHD risk.

HIV disease progression, antiretroviral medication, drugs of abuse and CHD risk: Univariate analyses were performed to identify significant associations between HIV disease status, HIV treatment regimens and the types and frequency of drugs of abuse. As shown in Table 3, these analyses show a significant association between the increasing viral load and the risk of metabolic syndrome ( $\mathrm{OR}=1.61 ; 95 \% \mathrm{CI}: 1.02$, 2.54; $\mathrm{p}=0.042)$, high fasting glucose $(\mathrm{OR}=1.28 ; 95 \%$ CI:1.03,1.58; $\mathrm{p}=0.023)$ and low HDL $(\mathrm{OR}=1.37 ; 95 \%$ CI:1.03, 1.81; $\mathrm{p}=0.03)$. Viral load was also found to be inversely correlated with serum cholesterol levels ( $\mathrm{r}=-$ $0.21, \mathrm{p}=0.023$ ) (not shown in the table). There did not appear to be a significant relationship between increased levels of viral load and plasma triglycerides, or blood pressure.

Other factors that contributed significantly to CHD risk were age, which was associated with high blood pressure $(\mathrm{OR}=1.1 ; 95 \% \mathrm{CI}: 1.01,1.19 ; \mathrm{p}=0.024)$, high serum triglyceride $(\mathrm{OR}=1.07 ; 95 \% \mathrm{CI}: 1.01,1.14$; $\mathrm{p}=0.024)$ and cholesterol $(\mathrm{OR}=1.09 ; 95 \% \mathrm{CI}: 1.01$, 1.18; $\mathrm{p}=0.019)$. Obesity, defined as BMI $>27 \mathrm{~kg} / \mathrm{m}^{3}$, was associated with metabolic syndrome $(\mathrm{OR}=1.19$; 95\% CI: 1.07, 1.32; $\mathrm{p}=0.001)$, high serum cholesterol $(\mathrm{OR}=1.09 ; 95 \% \mathrm{CI}: 1.00,1.20 ; \mathrm{p}=0.05)$ and central obesity (OR=1.88; 95\% CI:1.46, 2.42; $\mathrm{p}=0.001)$. Male gender was significantly associated with low levels of HDL (OR=0.42; 95\% CI:0.18, 0.98 ; $\mathrm{p}=0.044)$, metabolic syndrome ( $\mathrm{OR}=0.28 ; 95 \%$ CI:0.10, 0.80; $\mathrm{p}=0.017$ ), and central obesity (OR=0.07; 95\% CI:0.03, $0.21 ; \mathrm{p}=<0.001)$. HAART with or without PI did not contribute to either the 10-year CHD risk or metabolic syndrome in this cohort, and CD4 count was not significantly related to any of the variables analyzed (not shown in tables).

C-reactive protein (CRP), an independent CHD risk factor and a marker of inflammation, was significantly higher in participants with low levels of HDL (7.6 $\pm 10.6 \mathrm{SD}, \mathrm{p}=0.008)$ than in those who did not have overly low levels of HDL (2.4 \pm 2.5 SD). In multivariate analysis, abnormal CRP $\left(>3 \mathrm{mg} \mathrm{L}^{-1}\right)$ was significantly associated with low HDL (OR=1.18; 95\% CI:1.04,1.35; $\mathrm{p}=0.012$ ) and this association remain significant after controlling for gender, age, CD4 count, viral load, obesity, HAART and the use of protease inhibitors (not shown in tables).

Analysis of the relationship between drugs of abuse and CHD risk factors indicate that participants who are heavy cocaine/crack users are significantly less likely to be on HAART $(35.3 \%, \mathrm{p}=0.015)$ than those who are not heavy drug users $(15.5 \%)$. Regarding the univariate association of drug abuse with CHD risk factors, heavy cigarette use was significantly associated with low HDL (OR=3.06; CI:1.18, 7.95; p=0.02). Heavy use of cigarettes and crack/cocaine was inversely associated with obesity defined ad BMI of $>27 \mathrm{~kg} / \mathrm{mm}^{3}$ (OR=0.84, 95\% CI: 0.67, 0.99; $\mathrm{p}=0.049$; OR=0.43, 95\% CI: 0.19 , $0.98 ; \mathrm{p}=0.044$, respectively), while use of marijuana tended to be associated with central obesity $(\mathrm{OR}=2.25$; CI: $0.96,1.67 ; \mathrm{p}=0.08)$. 
Am. J. Infectious Dis. 2 (3): 173-179, 2006

Table 1: Prevalence of CHD risk factors for men and women in a cohort of HIV-seropositive drug users in Miami

\begin{tabular}{|c|c|c|c|c|}
\hline CHD Risk Factors & Total $n=118$ & Men $n=87$ & Women $n=31$ & p-value \\
\hline 10 -year risk \% Mean $\pm \mathrm{SD}$ & $4.8 \pm 5.7 \%$ & $5.9 \pm 6.1 \%$ & $1.7 \pm 2.4 \%$ & $<0.001$ \\
\hline 10 -year risk $\geq 10 \%$ & $12.9 \%$ & $16.5 \%$ & $3.2 \%$ & 0.06 \\
\hline Metabolic Syndrome $(\geq 3$ risk factors are met) & $15.1 \%$ & $10.3 \%$ & $29.0 \%$ & 0.013 \\
\hline Abdominal obesity (Waist $>102 \mathrm{~cm}$ in men and $>88 \mathrm{~cm}$ in women) & $20.5 \%$ & $8.1 \%$ & $54.8 \%$ & $<0.001$ \\
\hline High serum triglycerides ( $\geq 150 \mathrm{mg} / \mathrm{dL}$ ) & $34.5 \%$ & $34.1 \%$ & $35.5 \%$ & n.s. \\
\hline Low HDL $(\leq 40 \mathrm{mg} / \mathrm{dL}$ in men and $\leq 50 \mathrm{mg} / \mathrm{dL}$ in women $)$ & $45.7 \%$ & $40.0 \%$ & $61.3 \%$ & 0.042 \\
\hline High blood pressure $(\geq 130 / 85 \mathrm{mmHg})$ & $15.3 \%$ & $14.9 \%$ & $16.1 \%$ & n.s. \\
\hline High Systolic blood pressure $(\geq 130 \mathrm{mmHg}$ ) & $11.9 \%$ & $11.5 \%$ & $12.9 \%$ & n.s. \\
\hline High serum glucose ( Fasting blood glucose of $\geq 110 \mathrm{mg} / \mathrm{dL}$ ) & $18.6 \%$ & $18.4 \%$ & $19.4 \%$ & n.s. \\
\hline High total serum cholesterol $(\geq 200 \mathrm{mg} / \mathrm{dL})$ & $19.8 \%$ & $21.2 \%$ & $16.1 \%$ & n.s. \\
\hline
\end{tabular}

Table 2: CHD risk and HIV status in HIV-seropositive drug users with and without metabolic syndrome

\begin{tabular}{lccc} 
& With metabolic syndrome & Without metabolic syndrome & M- value \\
\hline Variables & Mean \pm SD & $4.2 \pm 4.2 \%$ & n.s. \\
\hline 10 -year risk \% & $8.0 \pm 10.2 \%$ & $10.2 \%$ & 0.041 \\
10 -year risk $\geq 10 \%$ & $27.8 \%$ & $24.2 \pm 4.0$ & $<0.001$ \\
Body Mass Index $\left(\mathrm{kg} / \mathrm{m}^{3}\right)$ & $28.6 \pm 4.1$ & $346 \pm 268$ & n.s. \\
CD4 cell count $\left(\mathrm{cell} / \mathrm{s} / \mathrm{mm}^{3}\right)$ & $264 \pm 223$ & $9.2 \pm 2.4$ & 0.07 \\
Viral $\operatorname{load}\left(\log _{10}\right.$ copies $\left./ \mathrm{ml}\right)$ & $10.3 \pm 2.0$ & & \\
\hline
\end{tabular}

Table 3: Univariate and multivariate analyses of CHD risks significantly associated with viral load

\begin{tabular}{llll}
\hline Univariate Analyses on Viral load $\left(\log _{10}\right.$ copies $\left./ \mathrm{ml}\right)$ & Odds Ratios & 95\% CI & p-value \\
\hline With metabolic syndrome $(\geq 3$ risk factors are met) & 1.61 & $1.02,2.54$ & 0.042 \\
With high glucose (Fasting blood glucose of $\geq 110 \mathrm{mg} / \mathrm{dL})$ & 1.28 & $1.03,1.58$ & 0.023 \\
With low HDL $(\leq 40 \mathrm{mg} / \mathrm{dL}$ in men and $\leq 50 \mathrm{mg} / \mathrm{dL}$ in women) & 1.37 & $1.03,1.81$ & 0.03 \\
\hline Multivariate Analyses on Viral load $\left(\log _{10}\right.$ copies/ml) & & & 0.023 \\
\hline With metabolic syndrome* $(\geq 3$ risk factors are met) & 2.23 & $1.12,4.47$ & 0.042 \\
With high glucose* (Fasting blood glucose of $\geq 110 \mathrm{mg} / \mathrm{dL})$ & 1.61 & $1.02,2.55$ & 0.046 \\
With low HDL** $(\leq 40 \mathrm{mg} / \mathrm{dL}$ in men and $\leq 50 \mathrm{mg} / \mathrm{dL}$ in women) & 1.41 & $1.01,1.98$ & \\
\hline
\end{tabular}

*Models controlled for age, gender, smoking, protease inhibitors, BMI, and CD4 cell count

** Models controlled for age, gender, smoking, BMI, and CD4 cell count

As shown in Table 3, the effect of viral load on CHD risk factors was also examined in multivariate models. In a multivariate regression, increased viral load remained associated with metabolic syndrome $(\mathrm{OR}=2.23, \quad 95 \% \quad \mathrm{CI}: 1.12, \quad 4.47 ; \mathrm{p}=0.023)$ after controlling for gender, age, smoking, PI exposure, BMI and CD4. In addition, increasing viral load was associated with higher blood glucose levels $(\mathrm{OR}=1.61$, 95\% CI: 1.02, 2.55; $\mathrm{p}=0.042)$ and lower HDL $(\mathrm{OR}=1.41 ; \quad 95 \% \quad \mathrm{CI}: 1.01, \quad 1.98 ; \mathrm{p}=0.046)$ after controlling for gender, age, smoking, BMI and CD4 cell count.

Higher BMI was the only factor that remained significantly associated with higher serum cholesterol levels $(\mathrm{p}=0.040)$ in a regression model that included viral load, age, gender, smoking, CD4 cell count, PI use, marijuana and cocaine/crack use.

The estimated effect of protease inhibitors was determined with sequential MANOVA models that included age, gender, smoking, viral load, CD4 cell count and BMI. After controlling for these variables, use of PI was still significantly related to high levels of triglyceride (estimated effect $=95.81 ; 95 \%$ CI:39.40, $152.21 ; \mathrm{p}<0.01)$

\section{DISCUSSION}

The results of this study demonstrate that the prevalence of metabolic abnormalities and CHD risk in our cohort of HIV infected chronic drug users is in the range of results published for other HIV infected cohorts. The risk of CHD, however, was considerably higher in participants with metabolic syndrome. Our cohort of drug abusers had a relatively high mean viral load. Increasing viral load was significantly associated with metabolic syndrome, high fasting glucose and low HDL levels. Other factors contributing to CHD risk were age, male gender, the use of protease inhibitors and obesity. Of the drugs of abuse heavy cigarette use was associated with low HDL levels. Marijuana use on the other hand, was associated with obesity, although not significantly, while cigarette smoking and crack/cocaine use were inversely and significantly associated with obesity.

The 10-year CHD risk was calculated using the algorithms developed in the Framingham study to estimate cardiovascular disease risk and validated in the general population. The score takes into account the following parameters: age, gender, total cholesterol, HDL-cholesterol, systolic blood pressure, elevated fasting glucose and smoking ${ }^{[12]}$. The score has been shown to accurately predict myocardial infarction rates in the Framingham Study ${ }^{[12]}$ and in HIV infected individuals receiving $\mathrm{HAART}^{[19]}$. CHD risk studies in HIV infection showed that while age, gender and smoking were the primary risk factors, adverse effects of HAART added metabolic complications and a substantial risk ${ }^{[19,20]}$. 
The prevalence of a 10-year CHD risk in the HIV seropositive population of chronic drug users in Miami $(4.8 \% \pm 5.7)$ was similar to the $4.1-7.6 \%$ previously reported for an HIV infected cohort and 5.3\% in a matched control group of HIV seronegative men and women from the Framingham data ${ }^{[21]}$. The 10-year CHD risk for our HIV infected cohort of drug users was also similar to the overall rate $(5 \%)$ reported for a homeless drug-using HIV seronegative cohort in Toronto $^{[22]}$. The CHD risk was significantly lower among the HIV infected women drug users $(1.7 \% \pm 2.4$ $\mathrm{SD}$ in women vs. $5.9 \% \pm 6.1 \mathrm{SD}$ in men, $\mathrm{p}=0.001$ ), which appears to be mainly due to their gender and to the pre-menopausal mean age of the women of $39.4 \pm$ 7.3 SD years ${ }^{[23]}$.

Despite the lower CHD risk, the prevalence of metabolic syndrome was significantly higher among the women ( $29 \%$ vs. $10.3 \%$ among men, $\mathrm{p}=0.013$ ), most likely due to the high rates of abdominal obesity, higher BMI and higher rates of low HDL levels among women. These results are in agreement with a report from another urban HIV positive cohort, which shows similar rates of obesity among HIV infected women ${ }^{[24]}$. The overall prevalence of $15.1 \%$ of metabolic syndrome in our cohort, however, was lower than the estimated $22 \%$ prevalence in the US general population $^{[7]}$ and the $33.1 \%$ prevalence of metabolic syndrome estimated by Bruno and colleagues ${ }^{[9]}$ in HIV infected patients on HAART.

Participants with metabolic syndrome had a significantly higher estimate of 10-year CHD risk of $\geq 10 \%(27.8 \%, \mathrm{p}=0.041)$ than those without metabolic syndrome $(10.2 \%)$. This is in agreement with earlier findings that show that metabolic syndrome is an independent cardiovascular risk factor, with a significant 3 -fold increase in risk for coronary heart disease and stroke and a markedly increased cardiovascular mortality in both men and women. In addition, Isomaa and colleagues ${ }^{[1]]}$ also demonstrated that cardiovascular morbidity and mortality associated with this cluster of risk factors was greater than those related to each component alone. The risk factors that significantly influenced the metabolic syndrome in our cohort were female gender, central obesity and low HDL levels. The apparent paradox in our findings of the low 10-year CHD risk in women, while it was predominantly the women who had the metabolic syndrome and consequently, higher percent of 10-year CHD risk, reflects on one hand the lower risk in females because of their gender and age using the 10year CHD risk algorithm, while the estimation of metabolic syndrome does not take age and gender into consideration. The analyses indicated however, that the $29 \%$ of the women in our cohort with metabolic syndrome have an increased CHD risk.

A primary finding in this study is the observation that increasing viral load was significantly associated with metabolic syndrome, high fasting glucose and low
HDL levels and that viral load was inversely associated with total cholesterol in our cohort of HIV infected drug users. Our findings are consistent with recently reported data in HIV infected women showing a significant inverse association between viral load and serum cholesterol levels ${ }^{[24]}$ and with results from another study ${ }^{[25]}$ that showed an association between higher HIV RNA levels and lower HDL cholesterol in antiretroviral-naïve HIV infected inner city men and women and suggested that high viral replication has a direct effect on serum lipid levels. In addition, other investigators ${ }^{[14,26]}$ have proposed a possible etiological link between inflammation caused by viruses and endothelial dysfunction, which may increase cardiovascular risk by eventually producing clinical atherosclerosis. Our findings also contribute to this hypothesis, as CRP, an independent predictor of $\mathrm{CHD}^{[27]}$ and a marker of inflammation ${ }^{[28]}$, was significantly higher in participants with low HDL when compared to those with adequate HDL. Abnormal CRP was also significantly associated with low HDL in our cohort. Elevated levels of CRP were not related to obesity, metabolic syndrome or other variables measured, in contrast to findings from a previous study ${ }^{[24]}$. Increased viral load in our cohort was associated with elevated levels of fasting glucose, which is likely to contribute to the 10-year CHD risk via the metabolic syndrome ${ }^{[29]}$.

The findings from our cohort indicate that a predominant portion of these HIV infected drug abusing participants have a high viral load and that increasing viral load was associated with metabolic syndrome, high fasting glucose and low HDL levels. The high mean viral load found in our cohort is consistent with previous reports suggesting that heavy use of illicit drugs has an influence on either adherence or effectiveness of antiretroviral medication and therefore, on viral control in intravenous drug users $^{[30,31]}$.

In our cohort, participants who are heavy cocaine/crack users are significantly less likely to be on HAART $(35.3 \%, \mathrm{p}=0.015)$ than those who are not heavy drug users (15.5\%). Moreover, drugs of abuse, particularly the combination of cocaine and ethano ${ }^{[18,32]}$ were previously reported to have an additive or synergistic effect on cardiovascular events. Concomitant cigarette smoking also has deleterious effects on myocardial oxygen supply and demand ${ }^{[33]}$. The drugs of abuse of choice of our participants, in order of prevalence were cigarette smoking, cocaine, alcohol and marijuana. Heavy use of cigarettes and crack cocaine were significantly and inversely associated with obesity in our cohort, which is consistent with our previous report linking heavy cocaine use with wasting ${ }^{[34]}$ and with the anorectic effect of these drugs ${ }^{[35-37]}$. Marijuana use on the other 
hand, a known appetite stimulant, tended to be associated with central obesity in our cohort, although not significantly. Evaluating the independent effects on coronary risk of both cocaine and marijuana in this cohort has been rather difficult, because the drugs may be used in combination or singly, depending on the availability. In addition, the purity, mode of ingestion and degree of absorption of street drugs varies greatly, making comparison less meaningful.

Other factors contributing to CHD risk were age, male gender, the use of protease inhibitors and obesity. These findings are consistent with previous studies of CHD risk factors in both HIV seronegative and seropositive populations ${ }^{[19,21,29,38]}$. The use of protease inhibitors appears to be associated with hypertriglyceridemia and an increased CHD risk ${ }^{[16]}$. The strong association between the use of protease inhibitors and elevated levels of triglycerides in our cohort is consistent with the previous findings and has an effect on the CHD risk via its contribution to the prevalence of metabolic syndrome. Obesity, through its association with central obesity, is also a contributing factor to metabolic syndrome and consequently to CHD risk, in our cohort ${ }^{[39]}$.

Overall, the findings from our cohort indicate that a predominant portion of these HIV infected drug abusing participants have a high viral load, suggesting that heavy use of illicit drugs has an influence on either adherence or effectiveness of antiretroviral medication and therefore, on viral control. Increasing viral load was associated with metabolic syndrome, high fasting glucose and low HDL levels. The prevalence of metabolic abnormalities and CHD risk is in the range of results published for other HIV infected cohorts. The 10 -year CHD risk was, however, considerably higher in participants with metabolic syndrome. Other factors contributing to CHD risk were age, male gender, abnormal levels of C-reactive protein, the use of protease inhibitors and obesity. Of the drugs of abuse heavy cigarette use was associated with low HDL levels. Marijuana use on the other hand, was associated with obesity, although not significantly, while cigarette smoking and cocaine use were inversely and significantly associated with obesity. Interventions to improve control of viral load and obesity are needed to lower the risks for CHD in this population exposed to chronic HIV-infection, HAART and drug abuse.

\section{ACKNOWLEDGEMENT}

Supported by the National Institute on Drug Abuse, Grant No. 1R01-DA-14966

\section{REFERENCES}

1. Gougeon, M.L., L. Penicaud, B. Fromenty, P. Leclercq, J.P. Viard and J. Capeau, 2004. Adipocytes targets and actors in the pathogenesis of HIV-associated lipodystrophy and metabolic alterations. Antivir. Ther., 9: 161-77.

2. Schmidt, H.H., G. Behrens, J. Genschel, M. Stoll, A. Dejam, R. Haas, M.P. Manns and R.E. Schmidt, 1999. Lipid evaluation in HIV-1-positive patients treated with protease inhibitors. Antivir Ther., 4: 163-70.

3. Behrens, G., A. Dejam and R.E. Schmidt, 1999. Impaired glucose tolerance, Beta cells function and lipid metabolism in HIV patients under treatment with protease inhibitor. AIDS, 13: F63-F70.

4. National Cholesterol Education Program (NCEP) Expert Panel on Detection, Evaluation, and Treatment of High Blood Cholesterol in Adults (Adult Treatment Panel III): Executive Summary of the Third Report of the National Cholesterol Education Program (NCEP) Expert Panel on Detection, Evaluation, and Treatment of High Blood Cholesterol in Adults (Adult Treatment Panel III). JAMA, 287:356-359, 2001.

5. Brewer, H.B.Jr., 2003. New features of the national cholesterol education program adult treatment panel III lipid-lowering guidelines. Clin. Cardiol., 26 (4 Suppl 3): III19-24.

6. Talbert, R.L., 2003. National Cholesterol Education Program Adult treatment panel III Role of the National Cholesterol Education Program Adult treatment panel III guidelines in managing dyslipidemia. Am. J. Health Syst. Pharm., 60 (13 Suppl 2): S3-8.

7. Ford, E.S., W.H. Giles and W.H. Dietz, 2002. Prevalence of the metabolic syndrome among US adults: Findings from the third National Health and Nutrition Examination Survey. JAMA, 287: 356-9.

8. Gazzaruso, C., P. Sacchi, A. Garzaniti, P. Frantino, R. Bruno and G. Filice, 2002. Prevalence of metabolic syndrome among HIV patients. Diabetes Care, 25: 1253-1254.

9. Bruno, R., C. Gazzaruso, P. Sacchi, C. Zocchetti, S. Giodanetti and A. Garzaniti et al., 2002. High prevalence of metabolic syndrome among HIV infected patients: Link with the cardiovascular risk. 31: 363-365.

10. Gazzaruso, C., R. Bruno, A. Garzaniti, S. Giordanetti, P. Fratino, P. Sacchi and G. Filice, 2003. Hypertension among HIV patients: prevalence and relationships to insulin resistance and metabolic syndrome. J. Hypertens., 7: 1377-82.

11. Isomaa, B., P. Almgren and T. Tuomi et al., 2001. Cardiovascular morbidity and mortality associated with metabolic syndrome. Diabetes Care, 24: 683-9.

12. Wilson, P.W., R.B. D'Agostino, D. Levy, A.M. Belanger, H. Silbershatz and W.B. Kannel, 1998. Prediction of coronary heart disease using risk factor categories. Circulation, 97: 1837-47.

13. Grunfeld, C., M. Pang and W. Doerrler, 1992. Lipids, lipoproteins, triglyceride clearance and 
cytokines in human immunodeficiency virus infection and the acquired immunodeficiency syndrome. J. Clin. Endo. Met., 74:1045-1052.

14. Blum, A., V. Hadas, M. Burke, I. Yust and A. Kessler, 2005. Viral load of the human immunodeficiency virus could be an independent risk factor for endothelial dysfunction. Clin. Cardiol., 28: 149-53.

15. Asztalos, B.F., E.J. Schaefer, K.V. Horvath, C.E. Cox, S. Skinner, J. Gerrior, S.L. Gorbach and C. Wanke, 2005. Protease inhibitor-based HAART, HDL and CHD-risk in HIV-infected patients. Atherosclerosis, [Epub ahead of print].

16. Hurwitz, B.E., N.G. Klimas, M.M. Llabre, K.J. Maher, J.S. Skyler, M.S. Bilsker, S. McPhersonBaker, P.J. Lawrence, A.R. Laperriere, J.M. Greeson, J.R. Klaus, R. Lawrence and N. Schneiderman, 2004. HIV, metabolic syndrome X, inflammation, oxidative stress, and coronary heart disease risk : role of protease inhibitor exposure. Cardiovasc. Toxicol., 4: 303-16.

17. Currier, J.S., A. Taylor, F. Boyd, C.M. Dezii, H. Kawabata, B. Burtcel, J.F. Maa and S. Hodder, 2003. Coronary heart disease in HIV-infected individuals. J. Acquir. Immune. Defic. Syndr., 33: 506-12.

18. Lange, R.A. and L.D. Hillis, 2001. Cardiovascular complications of cocaine use. N. Engl. J. Med., 345: 351-8.

19. Egger, M., C. Junghans, N. Friis-Moller and J.D. Lundgren, 2001. Highly active antiretroviral therapy and coronary heart disease: the need for perspective. AIDS, 15 (suppl. 5): S193-S201.

20. The D:A:D Study Group. Antiretroviral combination treatment and risk of myocardial infarction. Results from the D:A:D Study. N. Engl. J. Med., 349: 1993-2003.

21. Hadigan, C., J.B. Meigs, C. Corcoran, P. Rietschel, S. Piecuch, N. Basgoz, B. Davis, P. Sax, T. Stanley, P.W. Wilson, R.B. D'Agostino and S. Grinspoon, 2001. Metabolic abnormalities and cardiovascular disease risk factors in adults with human immunodeficiency virus infection and lipodystrophy. Clin. Infect. Dis., 32: 130-9.

22. Lee, T.C., J.G. Hanlon, J. Ben-David, G.L. Booth, W.J. Cantor, P.W. Connelly and S.W. Hwang, 2005. Risk factors for cardiovascular disease in homeless adults. Circulation, 111: 2629-35.

23. Lloyd-Jones, D.M., M.G. Larson, A. Beiser and D. Levy, 1999. Lifetime risk of developing coronary heart disease. The Lancet, 353: 89-92.

24. Dolan, S., C. Hadigan, K. Kililea, M. Sullivan, L. Hemphill, R. Lees, D. Schoenfeld and D. Grinspoon, 2005. Increased cardiovascular disease risk indices in HIV-infected women. JAIDS, 39: 44-54.

25. El-Sadr, W.M., C.M. Mullin, A. Carr, C. Gibert, C. Rappoport, F. Visnegarwala, C. Grunfeld and S.S. Raghavan, 2005. Effects of HIV disease on lipid, glucose and insulin levels: results from a large antiretroviral-naive cohort. HIV Med., 6: 114-21.

26. Shah, F., 2001. Link between infection and atherosclerosis: who are the culprits: viruses, bacteria, both, or neither? Circulation, 103: 5-6.
27. Cesari, M., B.W. Penninx, A.B. Newman, S.B. Kritchevsky, B.J. Nicklas, K. Sutton-Tyrrell, S.M. Rubin, J. Ding, E.M. Simonsick, T.B. Harris and M. Pahor, 2003. Inflammatory markers and onset of cardiovascular events: results from the Health ABC study. Circulation, 108: 2317-22.

28. Ridker, P.M., C.H. Hennekens and J.E. Buring et al., 2000. C-reactive protein and other markers of inflammation in the prediction of cardiovascular disease in women. N. Engl. J. Med., 342: 836-843.

29. Grinspoon, S.K., 2005. Metabolic syndrome and cardiovascular disease in patients with human immunodeficiency virus. Am. J. Med., 118 (Suppl. 2): 23S-28S.

30. Wood, E., J.S. Montaner, B. Yip, M.W. Tyndall, M.T. Schechter, M.V. O'Shaughnessy and R.S. Hogg, 2003. Adherence and plasma HIV RNA responses to highly active antiretroviral therapy among HIV-1 infected injection drug users. CMAJ, 169: 656-61.

31. Hinkin, C.H., D.J. Hardy, K.J. Mason, S.A. Castellon, R.A. Durvasula, M.N. Lam and M. Stefaniak, 2004. Medication adherence in HIVinfected adults: effect of patient age, cognitive status, and substance abuse. AIDS, 18(S1): 19-25.

32. Escobedo, L.G., A.J. Ruttenber, M.M. Agocs, R.F. Anda and C.V. Wetli, 1991. Emerging patterns of cocaine use and the epidemic of cocaine overdose deaths in Dade County, Florida. Arch. Pathol. Lab. Med., 115: 900-5.

33. Moliterno, D.J., J.E. Willard, R.A. Lange, B.H. Negus, J.D. Boehrer, D.B. Glamann, C. Landau, J.D. Rossen, M.D. Winniford and L.D. Hillis, 1994. Coronary-artery vasoconstriction induced by cocaine, cigarette smoking, or both. N. Engl. J. Med., 330: 454-9.

34. Campa, A., Z. Yang, S. Lai, L. Xue, J.C. Phillips, S. Sales and B. Page, 2005. HIV-related wasting in $\mathrm{HIV}$-infected drug users in the era of highly antiretroviral therapy. CID,:41. In press.

35. Li, M.D., S.L. Parker and J.K. Kane, 2000. Regulation of feeding-associated peptides and receptors by nicotine. Mol. Neurobiol., 22: 143-65.

36. Vee, G.L., G.B. Fink and G.H.Jr. Constantine, 1983. Anorexic activity of cocaine and coca extract in naive and cocaine tolerant rats. Pharmacol. Biochem. Behav., 18: 515-7.

37. Bedford, J.A., D.K. Lovell, C.E. Turner, M.A. Elsohly and M.C. Wilson, 1980. The anorexic and actometric effects of cocaine and two coca extracts. Pharmacol. Biochem. Behav., 13: 403-8.

38. Holmberg, S.D., A.C. Moorman, J.M. Williamson, T.C. Tong, D.J. Ward, K.C. Wood, A.E. Greenberg and R.S. Janssen, 2002. HIV outpatient study (HOPS) investigators. Protease inhibitors and cardiovascular outcomes in patients with HIV-1. Lancet, 360: 1747-8.

39. Dominiczak, M.H., 2003. Obesity, glucose intolerance and diabetes and their links to cardiovascular disease. Implications for laboratory medicine. Clin. Chem. Lab. Med., 41:1266-78. 